\title{
Artikel
}

\section{Inbreng van giften, de legitieme en de langstlevende echtgenoot}

Dr. mr. P.C. van Es*

\section{Inleiding}

De regeling van inbreng van giften in het kader van de verdeling van de nalatenschap (zie art. 4:229-233 van het Burgerlijk Wetboek, BW) moet scherp worden onderscheiden van de regeling van inkorting van giften in het kader van de legitieme (zie art. 4:89-90 BW). Een van de vragen die in deze bijdrage aan de orde komt, is of er samenloop tussen beide regelingen mogelijk is en zo ja, op welke wijze beide regelingen elkaar in dat geval beïnloeden. Voorafgaand aan de bespreking hiervan in paragraaf 3 wordt in paragraaf 2 meer in zijn algemeenheid aandacht besteed aan de inbreng van giften, waarbij de aandacht in het bijzonder uitgaat naar de regel van artikel 4:233 lid $2 \mathrm{BW}$, dat inbreng niet verplicht is voor zover de waarde van de gift groter is dan het aandeel van de erfgenaam. In paragraaf 4 wordt ten slotte voortgeborduurd op een artikel van Maasland dat vorig jaar in dit tijdschrift is gepubliceerd. ${ }^{1}$ Maasland wijst er in dit artikel op dat het niet altijd mogelijk of wenselijk is aan alle kinderen een (gelijke) vrijgestelde eigenwoningschenking te doen. Hij vraagt vervolgens aandacht voor de vraag welke mogelijkheden het instrument van de inbreng biedt om - na het doen van zo'n schenking aan één kind - alle kinderen uiteindelijk in financieel opzicht toch gelijk te behandelen. Maasland gaat er in zijn voorbeeld van uit dat de erflater/schenker alleen zijn kinderen als erfgenamen achterlaat. In deze bijdrage wil ik ook aandacht vragen voor het geval waarin naast

Dr. mr. P.C. van Es is universitair hoofddocent notarieel recht aan de Universiteit Leiden.

1. J.L.D.J. Maasland, Inbreng van giften, TE 2014, afl. 4, p. 71-74 de kinderen ook een langstlevende echtgenoot als erfgenaam wordt achtergelaten.

\section{Inbreng van giften}

\subsection{Algemene opmerkingen over inbreng van giften}

Hieronder volgen - voor het goede begrip van de lezer enige kernachtige opmerkingen over de regeling van inbreng van giften: ${ }^{2}$

1. Een verplichting tot inbreng van een gift bestaat alleen voor zover de erflater dit bij de gift of bij uiterste wilsbeschikking heeft voorgeschreven (art. 4:229 lid $1 \mathrm{BW}$ ).

2. Een bij gift opgelegde verplichting tot inbreng kan bij uiterste wilsbeschikking ongedaan worden gemaakt (art. 4:229 lid 2 BW).

3. De gever/erflater kan bepalen dat inbreng alleen ten behoeve van bepaalde erfgenamen zal geschieden. ${ }^{3}$

4. Giften vóór 1 januari 2003 gedaan aan een door de wet geroepen erfgenaam in de nederdalende lijn moeten worden ingebracht, tenzij bij de gift of bij een uiterste wilsbeschikking anders is bepaald (art. 139 Overgangswet NBW).

5. Er bestaat geen verplichting tot inbreng van giften wanneer de begiftigde geen erfgenaam is in de nalatenschap van de erflater (art. 4:229 lid $1 \mathrm{BW}$ ).

2. Voor een uitvoeriger bespreking zij verwezen naar het in noot 1 vermelde artikel van Maasland en de erfrechtelijke handboeken.

3. Dit volgt uit het gebruik van de woorden 'voor zover' in art. 4:229 lid 1 BW. Vgl. MvA II bij art. 4.5.4.3, Parl. Gesch. Vaststellingswet Erfrecht, p. 1041. Zie ook MvA II bij art. 4.5.4.3b, Parl. Gesch. Vaststellingswet Erfrecht, p. 1046. Zie over de wijze waarop de inbreng in zo'n geval plaatsvindt, MvA II bij art. 4.5.4.8, Parl. Gesch. Vaststellingswet Erfrecht, p. 1052. 
6. Niet de gift zelf, maar de maarde van de gift wordt ingebracht ten behoeve van de mede-erfgenamen (art. 4:229 lid $1 \mathrm{BW}$ ).

7. Giften worden in beginsel gewaardeerd naar het tijdstip van de prestatie, behoudens de in artikel 4:66 $\mathrm{BW}$ vermelde uitzonderingen (art. 4:233 lid 1 jo. art. 4:66 BW). Deze waarde wordt verhoogd met een rente van 6 procent per jaar vanaf de dag dat de nalatenschap is opengevallen (art. 4:233 lid $1 \mathrm{BW}$ ).

8. De waarde van de in te brengen gift komt bij de verdeling in mindering van het aandeel van de tot inbreng verplichte erfgenaam (art. 4:233 BW). Dit betekent dat wij onder het huidige recht alleen nog die vorm van inbreng kennen die onder het oude recht bekendstond als inbreng 'en moins prenant' en geregeld was in de laatste zin van artikel $1138 \mathrm{BW}$ (oud). De vraag wat er onder het 'aandeel' van de tot inbreng verplichte erfgenaam wordt verstaan en hoe dit wordt berekend, komt hieronder in de volgende paragraaf aan de orde.

\subsection{Artikel 4:233 lid 2 BW; inbreng gelimiteerd tot het aandeel van de erfgenaam}

Het 'aandeel' van een tot inbreng verplichte erfgenaam waarop de waarde van de gift op grond van artikel 4:233 lid $1 \mathrm{BW}$ in mindering komt, is een aandeel berekend in een fictieve massa die wordt gevormd door het saldo van de nalatenschap vermeerderd met de onderling in te brengen bedragen.

Wanneer A bijvoorbeeld een inbrengplichtige gift van 20 van zijn vader heeft verkregen en hij tezamen met zijn broer B erfgenaam is in vaders nalatenschap met een saldo van 80 , dan bedraagt het aandeel van $A$ in de fictieve nalatenschap 50. Op dit aandeel van 50 wordt 20 in mindering gebracht, zodat $\mathrm{A}$ uit de reële nalatenschap (van 80) 30 krijgt en B 50.

De hier in deze paragraaf aan de orde zijnde regel van artikel 4:233 lid $2 \mathrm{BW}$ houdt in dat een gift niet behoeft te worden ingebracht voor zover de waarde daarvan groter is dan het aandeel van de tot inbreng verplichte erfgenaam in de fictieve massa. ${ }^{4}$ Het berekenen van de precieze omvang van het in zo'n geval in te brengen bedrag vereist een kleine mathematische exercitie. Het probleem is namelijk dat de uitkomst van de rekensom (het in te brengen bedrag) mede de omvang van een van de delen van de som bepaalt (de fictieve massa). ${ }^{5}$ In de uitgave van Pitlo/Van der Burght, Erfrecht uit 1997 vindt men een algebraïsche formule die het bovenstaande illustreert. ${ }^{6}$ In het voorbeeld dat gehanteerd wordt, laat $\mathrm{E}$ drie kinderen na, A, B en C, en bedraagt de nalaten-

4. De ratio van de regel (die op grond van art. 1134 BW (oud) ook onder het oude recht gold) is te voorkomen dat een erfgenaam de nalatenschap verwerpt, enkel en alleen om te ontkomen aan de inbrengplicht. Vgl. Asser/Perrick 4 2013/663.

5. Zie ook MvA II bij art. 4.5.4.8, Parl. Gesch. Vaststellingswet Erfrecht, p. 1052, waar men leest: 'Dus wordt zo nodig het in te brengen bedrag - ook voor de berekening van de fictieve massa - dienovereenkomstig verminderd.'

6. Pitlo/Van der Burght, Erfrecht, Deventer: Kluwer 1997, nr. 228. Zie ook M.J.A. van Mourik, Erfrecht (Monografieën privaatrecht 1), Deventer: Kluwer 2013, nr. 85.6 schap 12.000. A heeft een inbrengplichtige gift van 20.000 ontvangen. Het aandeel van A in de fictieve massa bedraagt $1 / 3$ deel van $12.000+20.000(=10.666,67)$ en dit is minder dan de waarde van de gift van 20.000 . De formule waarmee men in dit geval de omvang van de inbrengplicht kan berekenen, luidt als volgt: $\mathrm{x}=(12.000$ $+x): 3 . x$ staat hierbij voor de waarde van het deel van de gift aan A dat moet worden ingebracht, en is 6000 . Een en ander betekent dat het aandeel in de fictieve massa van $A, B$ en C 6000 bedraagt en dat B en $C$ uit de reële nalatenschap van 12.000 ieder 6000 krijgen en A niets. Dit resultaat geeft aan dat de precieze bepaling van het inbrengplichtige bedrag in feite weinig betekenis heeft. Men kan namelijk ook gewoon zo redeneren dat zodra een tot inbreng verplichte erfgenaam een gift heeft gekregen waarvan de waarde groter is dan het aandeel van de erfgenaam in de fictieve massa, die erfgenaam de gift mag behouden, maar zijn recht verliest op een aanspraak op een deel van de reële nalatenschap.

Het bovenstaande voorbeeld is relatief eenvoudig omdat er slechts sprake is van één inbrengplichtige gift. Wanneer er sprake is van meerdere inbrengplichtige giften kan zich de situatie voordoen dat de waarde van een gift in eerste instantie niet groter is dan het aandeel van de erfgenaam in de fictieve massa, maar dat dit in tweede instantie wel het geval is als gevolg van de toepassing van de regel van artikel 4:233 lid $2 \mathrm{BW}$ ten aanzien van een andere gift.

Het volgende voorbeeld kan dit illustreren.

Erflater E heeft vier kinderen, A, B, C en D. Hij heeft de volgende inbrengplichtige giften gedaan: 100 aan A, 70 aan B en 40 aan C. D heeft geen gift ontvangen. Het saldo van de nalatenschap van $\mathrm{E}$ bedraagt 90 .

Het aandeel van $A, B, C$ en $D$ in de fictieve massa bedraagt $1 / 4$ van $(90+100+70+40)=75$. Dit is minder dan de waarde van de gift aan $A$, maar meer dan die van de giften aan B en C. Ten aanzien van A is de regeling van artikel 4:233 lid 2 BW derhalve van toepassing, zodat A in economische zin niet meedeelt in het saldo van de reële nalatenschap van 90 . A behoudt zijn gift en dit heeft ook gevolgen voor B. De volgende stap die namelijk gezet moet worden, is dat de fictieve massa exclusief de gift an A berekend moet worden en het aandeel van $\mathrm{B}, \mathrm{C}$ en $\mathrm{D}$ hierin moet worden bepaald. Dit andeel is $1 / 3$ van $(90+$ $70+40)=66,67$. Dit aandeel is kleiner dan de waarde van de gift aan B, zodat ook B zich kan beroepen op artikel 4:233 lid 2 BW en ook hij zijn gift van 70 mag behouden.

De exercitie moet nu weer worden herhaald voor $\mathrm{C}$ en $\mathrm{D}$, waarbij alleen nog rekening wordt gehouden met de gift aan C. De fictieve massa bedraagt dan 90 $+40=130$, en het aandeel van C en D hierin is 65 . $\mathrm{Nu}$ dit meer is dan de waarde van de gift aan $\mathrm{C}$ kan (in economische zin) tot verdeling van het saldo van de reële nalatenschap worden overgegaan. D (die 
geen inbrengplichtige gift heeft gekregen) krijgt 65 en C krijgt 65-40 $=25$.

Geredeneerd binnen het systeem van artikel 4:233 lid 2 BW moeten wij nu vaststellen dat de inbreng van zowel A als B 65 bedraagt. Dit is het bedrag dat eerst bij de reële nalatenschap wordt opgeteld - zodat de fictieve massa $90+65+65+40=260$ bedraagt en het aandeel van A, B, C en D hierin 65 - om vervolgens weer te worden afgetrokken van het aandeel van A en $B$ in de fictieve massa.

Het inbrengen van een gift betekent uitdrukkelijk niet dat een deel van de gift naar de te verdelen boedel vloeit. Inbreng is slechts een rekenkundige exercitie inhoudende dat een bepaald bedrag (de in te brengen waarde) wordt afgetrokken van het aandeel van de tot inbreng verplichte erfgenaam in de fictieve massa, waardoor zijn aanspraak op de reële nalatenschap wordt verminderd of tot nul gereduceerd. ${ }^{7} \mathrm{Wij}$ kunnen in het bovenstaande voorbeeld dus terecht zeggen dat $\mathrm{A}, \mathrm{B}$ en $\mathrm{C}$ - ondanks de inbreng van 65 , 65 respectievelijk 40 - hun giften voor het geheel behouden.

Een belangrijke vraag aan het einde van deze paragraaf is of A en B in het bovenstaande voorbeeld aan de verdeling van de nalatenschap moeten meewerken op straffe van nietigheid of vernietigbaarheid van de verdeling op grond van artikel 3:195 lid $1 \mathrm{BW}$.

Onder het oude recht werd algemeen aangenomen dat een tot inbreng verplichte erfgenaam op wie het met artikel 4:233 lid 2 BW vergelijkbare artikel $1134 \mathrm{BW}$ (oud) van toepassing was, diende mee te werken aan de verdeling. ${ }^{8}$ Kleyn brengt deze verplichting in verband met de keuze die de erfgenaam onder het oude recht had om in natura of 'en moins prenant' in te brengen; de erfgenaam moest alleen daarom al aan de verdeling meewerken om zijn keuze ten aanzien hiervan kenbaar te maken. ${ }^{9}$ In het huidige recht bestaat deze keuzemogelijkheid niet meer. Medewerking aan de verdeling door een erfgenaam die vanwege zijn inbrengverplichting (en het van toepassing zijn van art. 4:233 lid 2 BW) geen aandeel heeft in de nalatenschap, lijkt zinloos. Wel is het van belang dat een dergelijke erfgenaam in het kader van de verdeling een verklaring aflegt die inhoudt dat door de inbreng van giften zijn aandeel in de nalatenschap tot nul is gereduceerd. Ook zonder een dergelijke verklaring kan - in ons voorbeeld - de verdeling tussen C en D mijns inziens geldig en onaantastbaar tot stand komen,

7. Zie ten aanzien van inbreng 'en moins prenant' onder het oude recht in enigszins andere zin W.M. Kleyn, De boedelscheiding (diss. Leiden), Arnhem: Gouda Quint 1969, p. 376-378, die betoogt dat de verplichting tot inbreng niet het aandeel van de betrokken erfgenaam verkleint, maar dat deze verplichting als vordering van de nalatenschap in het kavel van de inbrengplichtige wordt gelegd, waarna de vordering door schuldvermenging tenietgaat. Deze benadering lijkt mij voor het huidige recht in strijd met de tekst van art. 4:233 lid $1 \mathrm{BW}$.

8. Zie bijv. Pitlo/Van der Burght 1997/228, Asser/Meijers \& Van der Ploeg, Erfrecht, Zwolle: W.E.J. Tjeenk Willink 1992, nr. 487a en Klaassen/Eggens \& Luijten, Erfrecht, Zwolle: W.E.J. Tjeenk Willink 1989, p. 376.

9. Kleyn 1969, p. 377 mits achteraf komt vast te staan dat $\mathrm{A}$ en $\mathrm{B}$ inderdaad met toepassing van de regel van artikel 4:233 lid $2 \mathrm{BW}$ tot inbreng verplicht waren. Men kan A en B alsdan immers niet aanmerken als 'deelgenoot' in de zin van artikel 3:195 lid $1 \mathrm{BW}$, aangezien zij geen enkel aandeel in de gemeenschap hebben. ${ }^{10} \mathrm{~A}$ en $\mathrm{B}$ blijven natuurlijk wel erfgenaam en hoewel zij geen 'aandeel' hebben in de gemeenschap van de nalatenschap, hebben zij ieder wel een 'erfdeel' van een kwart. Deze vaststelling is van belang in verband met de regeling van artikel 4:182 lid 2 BW inzake de aansprakelijkheid van erfgenamen voor de schulden van de erflater die niet met zijn dood tenietgaan. $^{11}$

\section{Inbreng van giften en de legitieme}

Het van toepassing zijn van de regeling van inbreng van giften kan in verschillende gevallen invloed hebben op de regeling van de legitieme. Hieronder wordt op een drietal van dergelijke situaties nader ingegaan.

\subsection{Inbreng gevolgd door inkorting}

Bij het van toepassing zijn van de regeling van artikel 4:233 lid 2 BW kan zich de situatie voordoen dat op het deel van de gift dat niet hoeft te worden ingebracht omdat het het aandeel van de betrokken erfgenaam overstijgt, alsnog kan worden ingekort.

Te denken valt aan het geval waarin $\mathrm{E}$ als enig erfgenamen zijn kinderen A en B achterlaat. Aan A heeft E een gift van 400 gedaan, onder de verplichting van inbreng, en het saldo van de nalatenschap bedraagt 100. A hoeft ingevolge artikel 4:233 lid $2 \mathrm{BW}$ niet meer dan 100 in te brengen en $B$ ontvangt het gehele saldo van de nalatenschap ad 100. De legitieme portie van A en B bedraagt echter $125(1 / 4$ x $[100+400])$. B kan nu op grond van artikel 4:89 BW nog 25 inkorten op de gift aan A.

Onder het oude BW gold voor dit soort situaties de wat curieuze regeling van artikel 1134 jo. artikel $1133 \mathrm{BW}$ (oud). Zij kwam erop neer dat de legitimaris (in ons voorbeeld B) 'ter zake van zijn verkorte erfrecht' de keuze had tussen inkorting op de gift aan A en het vorderen van een inbreng die meer bedroeg dan het erfdeel van B. ${ }^{12}$

\subsection{Inbreng, legitimaire massa en toerekening}

Het gegeven dat een erflater heeft bepaald dat een gift moet worden ingebracht, heeft geen invloed op de waardering van de gift bij de berekening van de legitimaire massa (als bedoeld in art. 4:65 BW) noch op de waardering van de gift bij toerekening hiervan op de legitieme

10. Anders Asser/Perrick 4 2013/670, waar evenals in de oudere drukken van dit werk staat te lezen dat 'ook ten aanzien van de erfgenaam, die door toepassing van de inbreng "en moins prenant" niets bij de verdeling van de nalatenschap zal ontvangen, zijn medewerking bij de verdeling vereist [is]'.

11. Zie in dit verband ook art. 4:232 lid 1 BW, dat bepaalt dat de aansprakelijkheid van de erfgenamen jegens de schuldeisers van de nalatenschap door een verplichting tot inbreng niet wordt gewijzigd.

12. Zie Hof Arnhem 7 april 1897, W 6992. 
portie volgens artikel 4:70 lid $1 \mathrm{BW}$. Inbreng van giften vermindert echter wel de waarde van hetgeen een tot inbreng verplichte begiftigde als legitimaris krachtens erfrecht heeft verkregen (waarover art. 4:71 BW). Een voorbeeld ter illustratie.

E heeft twee kinderen A en B, die zijn enig erfgenamen zijn. E heeft aan A een gift van 200 gedaan onder de verplichting deze in te brengen. Kort voor E's dood heeft $\mathrm{X}$ van $\mathrm{E}$ een gift van 800 verkregen. Het saldo van de nalatenschap bedraagt 200. De legitieme portie van $A$ en $B$ in deze nalatenschap bedraagt $1 / 4$ van de legitimaire massa ad $(200+200+800)=300$. Om de legitimaire vordering van $\mathrm{A}$ en $\mathrm{B}$ te berekenen moet hetgeen zij krachtens erfrecht en/of door giften hebben verkregen van de legitieme portie worden afgetrokken (art. 4:71 respectievelijk art. 4:70 BW). Om te bepalen wat A en B krachtens erfrecht hebben verkregen, moet de regel van inbreng van artikel 4:233 lid $1 \mathrm{BW}$ worden toegepast. Dit betekent dat het aandeel van B in de nalatenschap 200 bedraagt en dat van A nihil.

De legitimaire vordering van zowel A als B bedraagt nu 100. Die van B omdat op zijn legitieme portie van 300 de erfrechtelijke verkrijging van 200 in mindering wordt gebracht (art. 4:71 BW), en die van A omdat op zijn legitieme portie de gift van 200 in mindering wordt gebracht (art. 4:70 lid $1 \mathrm{BW}$ ).

$\mathrm{A}$ en $\mathrm{B}$ verkrijgen hun legitimaire vordering door inkorting op de gift aan X (art. 4:89 lid 1 BW).

\subsection{Inbrengplicht kan beroep door mede- erfgenaam op legitieme voorkomen}

De relatie tussen de regeling van inbreng van giften en die van de legitieme houdt ook in dat de verplichting tot inbreng een beroep op de legitieme door een mede-erfgenaam kan voorkomen.

Als voorbeeld nemen wij wederom A en B, die enig erfgenaam zijn van hun vader $\mathrm{E}$. A heeft van $\mathrm{E}$ een gift van 300 ontvangen en het saldo van de nalatenschap bedraagt 200. Wanneer de gift aan A nietinbrengplichtig is verklaard, kan B voor 25 inkorten op de gift aan A. B's legitieme portie bedraagt immers $1 / 4 \times(200+300)=125$. Uit de nalatenschap ontvangt B 100, zodat een legitimaire vordering van 25 resteert.

Wanneer E had bepaald dat A de gift diende in te brengen, ontstaat een ander beeld. A had dan 200 uit de nalatenschap ontvangen, zodat van een legitimair tekort geen sprake zou zijn geweest.

\section{Tot slot: inbreng van giften en de langstlevende echtgenoot}

Maasland heeft erop gewezen dat het instrument van de inbreng van giften de gelijke behandeling van kinderen niet kan bewerkstelligen wanneer een ouder slechts aan één van zijn twee kinderen een vrijgestelde eigenwoningschenking heeft gedaan. Inbreng voorkomt namelijk niet dat het begiftigde kind netto meer ontvangt dan het kind dat van de inbreng profiteert, omdat de laatste over zijn gehele verkrijging erfbelasting dient te betalen, terwijl het andere kind destijds over de schenking geen schenkingsrecht hoefde te betalen. De suggestie die Maasland doet om beide kinderen een gelijke nettoverkrijging te doen toekomen, is het maken van een prelegaat aan het kind dat geen gift heeft gehad, ter grootte van het geschonken bedrag, vrij van erfbelasting. ${ }^{13}$

Wanneer de schenkende ouder een inbrengplicht verbindt aan een gift aan een van zijn kinderen (A) en - anders dan in het voorbeeld van Maasland - ook nog een langstlevende echtgenoot als erflater zou achterlaten (L), wordt de gelijke nettoverkrijging door A en het andere kind B niet alleen ondergraven door de verschuldigde erfbelasting, maar ook door het feit dat de inbreng bij het van toepassing zijn van de wettelijke verdeling (waarover art. 4:13 lid $3 \mathrm{BW}$ ) er voor B slechts toe leidt dat hij een grotere vordering op zijn moeder verkrijgt dan A. ${ }^{14}$ Deze vordering is in beginsel pas opeisbaar bij de dood van L (art. 4:13 lid $3 \mathrm{BW}$ ), zodat er van echte gelijktrekking van de positie van $A$ en $B$ geen sprake is.

Men kan dit probleem langs twee wegen oplossen. In de eerste plaats kan worden bepaald dat de vordering van kind B voor dat gedeelte dat correspondeert met het door A ingebrachte bedrag van de schenking, direct opeisbaar is. ${ }^{15}$ De tweede mogelijkheid is te kiezen voor een prelegaat aan $B$ in plaats van het opleggen van een inbrengverplichting aan A.

Bij beide oplossingen geldt dat de positie van B nog steeds niet even sterk is als die van A. Zowel het krachtens het prelegaat verkregene als de geldvordering waarvoor de vervroegde opeisbaarheid geldt, kan namelijk op grond van artikel 4:30 lid 2 en 3 BW worden onderworpen aan een ten behoeve van $L$ gevestigd verzorgingsvruchtgebruik. Dit geldt uiteindelijk op grond van artikel 4:34 BW ook voor de door A verkregen gift, maar van toepassing van deze regeling kan pas sprake zijn wanneer L niet op grond van het bepaalde in artikel 4:29 en 4:30 BW in haar verzorgingsbehoefte kan voorzien.

13. Maasland 2014, p. 73.

14. Teneinde de positie van A en B zo veel mogelijk gelijk te trekken is het van belang te bepalen dat de inbreng van de gift aan $A$ alleen geschiedt ten behoeve van B en niet ten behoeve van L. Zie voor deze mogelijkheid noot 3 .

15. Zie voor deze mogelijkheid de slotzin van art. 4:13 lid 3 BW. 